\title{
NOMOS Y IUS COMO FUNDAMENTO DE LA POLIS GRIEGA Y LA CIVITAS ROMANA
}

\section{Nomos and Ius as foundation of the Greek Polis and the Roman Civitas}

\author{
RAFAEL GARCÍA SÁNCHEZ \\ Doctor Arquitecto. Profesor Asociado de Estética y Composición, Historia de la Arquitectura. Escuela \\ Técnica Superior de Arquitectura y Edificación. Universidad Politécnica de Cartagena (España) \\ rafael@sgbarquitectos.es
}

Recibido: $23 / 01 / 2017$

Aceptado: $17 / 03 / 2017$

\section{Resumen}

Polis y civitas suelen traducirse por ciudad, como si ambas se refiriesen a la estructura material. Sin embargo, polis y civitas no son propiamente realidades físicas sino de orden inmaterial. En este texto se pretende anotar la diferencia conceptual existente entre ambos términos. Una cuestión es la realidad urbanística, material y geométrica de la ciudad, y otra es su realidad religiosa, política, filosófica y sociológica de la que depende. Mientras que la polis está determinada por el nomos como principio formalizante, la civitas se articula en torno al ius. Es así como se entiende que polis y civitas puedan explicarse como distintas formas de comprender la convivencia y las relaciones sociales.

Palabras clave

Polis, civitas, nomos, ius, ciudad, Grecia, Roma. 


\begin{abstract}
Polis and civitas tend to translate is by city, as if both are questioned to the inmaterial structure. However, polis and civitas are not actual physical realities but immaterial order. This text aims to annotate the conceptual difference between both terms. A question is urban, material and geometric reality of the city, and another is their religious, political, philosophical and sociological reality which depends. While the polis is determined by the nomos as principle, the civitas is articulated in the lathe to the ius. This is how it is understood that polis and civitas may explain how different ways of understanding the coexistence and social relations.
\end{abstract}

\title{
Keywords
}

Polis, civitas, nomos, ius, city, Greece, Rome.

Referencia normalizada: GARCÍA SÁNCHEZ, RAFAEL (2017): “Nomos y Ius como fundamento de la Polis griega y la Civitas romana". Arte y Ciudad. Revista de Investigación, no 11 (abril), págs. 199-224. Madrid. Grupo de Investigación Arte, Arquitectura y Comunicación en la Ciudad Contemporánea, Universidad Complutense de Madrid.

Sumario: 1. Introducción. 2. Tomar la tierra: iustissima tellus. 3. El nomos: de lo fundacional a lo sociopolítico. 4. La polis: el punto de vista del oído. 5. La polis: el punto de vista del gens. 6. Los espacios políticos: el punto de vista de la Res-pública. 7.- Una civitas no es una polis: el punto de vista de la Concordia. 8. Conclusión. 9. Bibliografía.

\section{Introducción.}

¿Es un fenómeno exclusivo de los hombres vivir con sus semejantes? Rotundamente no, y así lo anotan tanto Platón como Aristóteles. Desde una cierta perspectiva, convivir con semejantes parece ser fruto de una limitación derivada de las condiciones de vida orgánica y compartida con los denominados animales sociales. Pero la convivencia puede articularse en distintas dimensiones, dando lugar a una vida meramente social y gregaria (como entre las ovejas, las abejas y, en general, los rebaños y manadas) o a una comunidad meramente política. A esta última posibilidad alude la expresión zoon politikon.

La condición humana es más bien política y no sólo debe entenderse como una conditio sine qua non, sino la conditio per quam, de toda forma de vida polí- 
tica, anota Arendt (1998: 22). Una traducción que vincule la expresión zoon politikon exclusivamente con lo social, en cierto modo, supone una alteración excesiva, pues para el mundo griego no existe ni concepto, ni palabra para la sociabilidad humana. El hombre, a diferencia de muchas especies animales, es un animal político, en cambio los animales son sociales pero no políticos. Ser un animal político significa que para desarrollar en plenitud su humanidad necesita de otros, pero esa relación está constituida desde la libertad y no desde la necesidad como sucede en el mundo animal. El calificativo de politikon no se le otorga al ciudadano por vivir en la polis sino por ser humano; no obstante, el lugar idóneo para serlo es la ciudad.

\section{Tomar la tierra: iustissima tellus.}

Carl Schmitt sostiene que desde tiempo inmemorial la tierra es la madre del derecho. Primero por su fertilidad pues la tierra posee una medida interna que conoce el campesino. Su esfuerzo de labranza y siembra son recompensados en justicia con el crecimiento y la cosecha. Segundo, porque la tierra que el hombre trabaja ofrece delimitaciones visibles que permiten distinguir los diferentes tipos de medidas internas. Tal es la diferencia entre campos, praderas o bosques. Tercero, porque sobre las delimitaciones anteriores se erigen vallados y cercas que son signos públicos de la ordenación y el asentamiento humanos. En definitiva, porque hay tierra y medida interna, cultivos y delimitaciones, vallados y parcelas, hay orden. Por eso, cuando tomamos la tierra fundamos el orden y con él el derecho, tal es el sentido de la expresión iustissima tellus (Schmitt, 2005: 21-22). Huelga decir que en las culturas arcaicas el mar, a diferencia de la tierra, no es el origen del orden y del derecho pues ni posee medida interna, ni es posible delimitarlo ni levantar marcas: "Sobre las olas, todo es ola (...) En el mar no rige ninguna ley" (Schmitt, 2005: 22, 23). Por eso el mar es el espacio para las actividades no ordenadas ni regladas como la aventura y la piratería.

Los primeros actos jurídicos, al menos en las sociedades urbanas, son los que se siguen de "tomar la tierra": la distribución del suelo, la propiedad pública o privada, en definitiva, los primeros títulos jurídicos y de propiedad. Fundar ciudades y crear colonias son en este sentido "tomas" de la tierra que siempre llevan consigo una primera medida que contiene todas las demás, creándose una propiedad suprema de la comunidad y por eso: 
Todas las ulteriores relaciones jurídicas con el suelo del territorio dividido por la raza o pueblo que lo ha tomado, todas las instituciones de la ciudad protegida por una muralla o de una nueva colonia están determinadas a partir de esta medida primitiva, y todo juicio autónomo que sea adecuado se origina en el suelo (Schmitt, 2005: 24).

"Tomar la tierra" se convierte, a decir de filósofos del Derecho como Vico, Locke y Kant en el gran hecho histórico por cuanto a partir de esa posesión se funda toda jurisdicción. Vico se refiere en Scienza nuova a la "divisione dei campi" (1839: 47); Locke afirma que "Government has a direct jurisdiction only over the land" (2003: 323), la esencia del poder político es, en primer término, la jurisdicción sobre la tierra; Kant sostiene en La Metafísica de las Costumbres que "la primera adquisición de una cosa no puede ser otra que la del suelo" (1989: 77 (VI, 261-2)). Para Arendt:

Antes de que los hombres comenzaran a actuar, tuvo que asegurarse un espacio definido y construirse una estructura donde se realizaran todas las acciones subsecuentes, y así el espacio fue la esfera pública de la polis y su estructura la ley; el legislador y el arquitecto pertenecían a la misma categoría (1998: 218).

Como se ha indicado, sobre la tierra se erigen vallados y cercas que hacen visible el primer ordenamiento de una comunidad estable, el radical title del que parecen nutrirse los demás preceptos y leyes. Al respecto, es reveladora la etimología del término griego nomos pues antes de ser superado con fines filosóficos y legales estuvo emparentado con el hecho inaugural de cualquier ordenamiento: la partición y división del espacio. Nomos en su sentido primigenio es un término espacial, no en vano debe su origen a la palabra nemein, que guarda relación con distribuir, poseer y habitar (Arendt, 1998: 92). Coincide con la expresión alemana nehmen que significa tomar, coger para después dividir y repartir lo que se ha tomado, para explotarlo o utilizarlo. La valla y la ley (que a decir de Schmitt y de Arendt guardarían una relación de causa y efecto) se sintetizan en el término nomos: porque existe un nomos es posible medir y al cabo, repartir y dividir, en suma: legislar. Para tomar la tierra, para fundar una ciudad o una colonia es imprescindible la existencia de un nomos que convierta el mero espacio en la ordenación política y social de un pueblo (Schmitt, 2005: 52). No es casualidad que Heráclito hubiese enlazado la ley y la valla porque en el fondo una ley es la expresión de un límite; legislar es de alguna manera delimi- 
tar: "machestai chré ton démon hyper tou nomou hokósper teicheos, el pueblo ha de luchar tanto por la ley como por la valla" (22B 44DK)․․

Para Aristóteles el nomos sigue relacionado con la medida primera (espacial) de la que se derivan todas las demás. Si se lee detenidamente el libro IV de la Política se percibe la relación del nomos espacial con la distribución y delimitación original del suelo, manteniendo su sentido primigenio de toma de tierra, de asentamiento y ordenación que ha destacado Carl Schmitt.

Dentro del nomos tenía lugar lo sagrado, lo separado de lo ordinario y corriente, y lo que da sentido al mundo y ordena el caos (Burkert, 2009). Franquear la valla y la cerca, adentrándose impunemente en el fundamento de la ley de ordenación, sería sospechoso de falta de cordura. Al respecto es reveladora la etimología de la palabra lira, pues tiene la raíz indoeuropea leis que significa huella, vestigio, marca, y guarda relación con la traza o el surco que delimitaba la ciudad y unas propiedades de otras. Cruzar la lira daría lugar al delirio, de-lirare (Rykwert, 1985: 129; Coulanges, 2009: 76-77). Las poleis griegas son ciudades donde es sabido que atravesar los límites es considerado un acto delirante y no en vano, tal y como nos cuenta Platón en Fedón (114e118a), Sócrates asume la condena a muerte antes que el destierro porque sabe que si incumpliese la ley, si se saliese del surco, es decir, de la lira, perdería la cordura. No es casual que una de las preocupaciones de Platón y Aristóteles en el orden de lo urbano sea que la polis no crezca demasiado, porque un crecimiento ilimitado daría lugar a la disolución de los límites.

\section{El nomos: de lo fundacional a lo sociopolítico.}

El término nomos no mantuvo indefinidamente su sentido primigenio, vinculado al espacio y a la ordenación. En la época de Platón y de Aristóteles había adquirido un sentido normativo, el de los nomoi. En ello parece haber influido notablemente la tensión entre nomos y physis con lo que el Ser acabó separándose del Deber, anulándose su sentido original, orientándose hacia una dimensión normativa y dispositiva (Schmitt, 2055: 50).

\footnotetext{
${ }^{1}$ Más adelante se verá que la palabra romana Lex contiene un significado completamente distinto al de nomos. El término Lex refiere una relación formal entre personas, más que la valla o cerca que separa a unas de otras. No obstante, el límite y su dios, Terminus, que dividía el agrum publicum a privato (Livio) se tenían como más venerados que sus homólogos theoi horoi griegos.
} 
De todas formas, el principio rector que explica el modo peculiar griego de coexistencia siguió siendo el nomos. Ese modo de coexistencia recibe el nombre de koinonía (comunidad) política. Conviene anotar que ésta no es continuación de las formas previas de coexistencia que se conocían en Siria, en Persia, en Babilonia o en Egipto ${ }^{2}$. Grecia se distingue de las formas políticas orientales como una novedad radical, dado que el mundo griego ha encontrado una manera de existir, fundada en y desde el nomos, estando referenciado al logos y no a la voluntad de los poderosos. Ciertamente, para ello hace falta una sophia, un modo nuevo de sabiduría distinto a los anteriores.

La cultura griega descubre una forma inédita de acercamiento a la realidad que le permite desvelar facetas de la misma que sólo se hacen evidentes en el modo de acercarse a ellas. Se trata de un acercamiento que descubre que hay aspectos de las cosas que les pertenecen en propiedad. Esta es la principal intuición helénica: los seres poseen atributos que les pertenecen en propiedad. Cuando un mesopotámico se enfrentaba a una piedra, sabía que ésta pesaba y que haría falta esfuerzo para desplazarla. El descubrimiento griego consiste en advertir, no tanto que las piedras pesan sino, que "el peso" es algo suyo: la realidad tiene características que le son propias y así es como aparecen expresiones del tipo "el ser propio de", "la mismidad", etc.

Con este modo inédito de acercamiento a la realidad se descubren nuevas áreas como el cosmos y el caos, el ser inteligente parmenídeo, lo asomático de las matemáticas euclidianas o el ser verdadero de Demócrito. De modo que las argumentaciones con sede en el simbolismo arquetípico reeditado ritualmente en el simbolismo religioso o en el meramente aparente, fueron cediendo paso a un modo especulativo del pensar, basado en conceptos abstractos que no se alcanzan necesariamente a través de la experiencia inmediata, como de hecho sucede en el apeiron unificador y rector del devenir de Anaximandro, o en los elementos de Empédocles. Una de esas regiones es la del hombre, resultando que su viabilidad social es política, a saber: cívica. En solitario el hombre es un "hombre remoto" (Marín, 1997 b: 39-92) “o bien un ser inferior o más que un hombre" (Aristóteles, 2009: I, 2, 1253a).

\footnotetext{
${ }^{2}$ Aristóteles se refiere en la Política al caso de Babilonia. En estos imperios el nomos no se distingue de la voluntad de los poderosos que imponen por la fuerza, pero no por el bien común (Aristóteles, 2009: III, 3, 1276a-1276b).
} 
El hombre heleno se ha abierto a un nuevo mundo que comprende según conceptos porque realiza una consideración pensante. Un mundo en que el nous (Choza, 2014: 191) ${ }^{3}$ recae sobre el ser y no sobre las cosas: una praxis que se basta a sí misma, una actitud theorética que el hombre ejercita por sí mismo. Sólo desde este tipo de actitud y en el seno de la polis adquiere el hombre la libertad y la autosuficiencia (autarkeia).

La hazaña griega consiste en que la comunidad política se organiza en unidad de acción y decisión desde una última instancia universal: el nomos. El nomos es lo que hace surgir un modo nuevo de comunidad y lo que determina la unidad interna de la polis. El vivir político será conforme al nomos: todo individuo vive en virtud del nomos y conforme al nomos y es ante él ante quien responde.

El nomos no es la physis. La physis es lo inscrito en el ser de las cosas, sin embargo, el nomos es el producto de la razón; es aquello cuyo origen es la reflexión y la consideración humanas. La distinción entre physis y nomos es la que se da entre naturaleza y cultura. Es la razón lo que permite descubrir la verdad de lo natural y esa verdad es común, por eso, someterse a la ley ${ }^{4}$ es someterse a la inteligencia ¿Qué es la ley? la razón emancipada del apetito.

Todo ello forma parte del advenimiento del pensamiento conceptual, un modo de pensar que se propone descubrir la razón última de las cosas. A partir del hallazgo del pensamiento especulativo y conceptual, es posible encontrar las homogeneidades, las constantes y las leyes internas que regulan el comportamiento de las cosas y al cabo, del mundo. Para ello hace falta un modo insólito de acercarse a ellas. Ese es el modo que se desarrolla en Grecia y no es una cuestión irrelevante porque entonces, esa manera de acercarse a las cosas es la manera griega de hacerlo, que tendrá repercusiones sobre la noción de polis y de polities muy vinculada al gens y que no hallará propiamente equivalencia en las versiones romanas de civitas y civis. Una polis no es una civitas, como más adelante se verá y ni una ni otra son, en sentido estricto, la forma física de la ciudad.

\footnotetext{
${ }^{3}$ El nous no son los primeros principios sino la inteligencia que los capta.

${ }^{4} \mathrm{Si}$ la ley se deriva exclusivamente de la naturaleza, entonces se identifica con ella (physis) sin residuos, y la ley es entonces inalterable. Si deriva exclusivamente del logos, entonces es pura arbitrariedad y su validez queda sujeta a ser acorde con el logos del sujeto que la produjo.
} 


\section{La polis política: el punto de vista del oído.}

La toma de la tierra y con ella la creación de un espacio de comparecencia pública ordenado y ordenante, materializado por arquitectos y legisladores bien puede entenderse como objetivación y manifestación del nomos. Aunque el nomos no es propiamente la ciudad física, da lugar a la creación de la polis que debe entenderse como la organización de la gente "tal como surge de actuar y hablar juntos". Tal es el sentido de la polis, no importando tanto lo físico y material: "compartir palabras y actos" (Arendt, 1998: 221).

Cabría pensar ahora si la definición de hombre como zoon politikon (Aristóteles, 2009: I, 2, 1253a) puede darse con anterioridad a la creación de poleis griegas en las costas mediterráneas, por ejemplo, en las ciudades sumerias o babilónicas donde no hay posibilidad de compartir discursos y acciones. Para el estagirita el hombre es un animal político, cuya materialización se torna efectiva si hay polis o exclusivamente en la polis. Bárbaros serían entonces los que no viven en las poleis o los que viven en otras que no se regulan del mismo modo que las griegas. Tampoco serían vivientes políticos los niños, las mujeres y los débiles entre otros, como no lo son los dioses ni los seres vivientes de otra especie (Aristóteles, 2009: I, 2, 1252b-1253a).

Ciertamente, si hay algún hecho capaz de inaugurar una época con una proyección casi ilimitada en el tiempo, ese parece ser la fundación de la polis y no como una suerte de asentamiento cualquiera que permite a los hombres trabajar, rezar, sacrificar, guarecerse y defenderse en equipo. La novedad de este hecho estriba, por un lado en el descubrimiento de un tipo de saber capaz de obtener propiedades homogéneas y constantes, leyes del mundo y de la realidad, y por otro en que la polis se funda, no tanto sobre la base de que allí puedan comparecer los iguales como que aquellos que lo hacen son escuchados pues allí se comparten las palabras. No basta entonces con hablar; hay que decir y para ello resulta inevitable ser escuchado de verdad. La polis es el lugar en el que se escucha porque allí, en ese espacio público que es el ágora, existen otros que son conciudadanos, no sólo por ser aristócratas y estar emancipados de la necesidad; no sólo por tener patrimonio, por ser virtuosos o por tener palabra. Allí comparecen los que tienen el derecho a decir, porque saben que son escuchados; los que se han dado el derecho de "isegoría, del que teóricamente disfrutaban todos los atenienses para hablar en el ágora, o en cualquier lugar donde se tomaran decisiones políticas" (Sancho, 2009: 232) y no los que tenien- 
do capacidad de fonación no tiene capacidad de discurso: Por eso, "porque les asiste el derecho a decir y ser escuchados pueden decidir" (Roiz, 2002: 4).

A la polis asisten solamente los que tienen una vida o una historia que contar, en suma: los que tienen un relato o, políticamente, un discurso. Como ya se ha indicado, y a decir de Aristóteles, ni infantes ni mujeres ni esclavos ni bárbaros pueden pertenecer a la polis (Aristóteles, 2009: I, 2, 1253b). Éstos son los que no saben hablar o hablan palabras rotas y sueltas, palabras que no se pueden juntar ni unir como hacen los que saben. Por eso, los niños, las mujeres, los esclavos y los bárbaros no tienen capacidad de discurso, balbucean, "ba-ba-ba". Pertenecen a la polis los que pueden juntar sus palabras y sus vidas y darles unidad bajo la forma de un relato y de un discurso (Marín, 1997a: 21-51).

Los niños e infantes no tienen historia, por eso no la pueden contar. La vida de las mujeres (domésticas) es irrelevante porque su trabajo es cíclico y no acumulativo, no genera plusvalía antropológica que diría Marx. Ellas solo pueden repetir las mismas acciones cíclicamente pero sin poder otorgarles unidad a lo que hacen, que es como no saber por qué lo hacen. Los esclavos tampoco pueden comparecer en la polis porque sus vidas no son las de ellos sino las de sus amos que son las que pueden contarlas (Aristóteles, 2009: I, 4, 1254a; I, 5, 1254b1255a; I, 13, 1260a). La vida que llevan no la protagonizan o dicho así: el principio activo que mueve su vida activa no está en ellos, está en sus amos. Lo que un esclavo ve y oye es a su amo pero no a sí mismo. Finalmente, los bárbaros tampoco pueden asistir a la polis, no pueden ser ciudadanos. Tienen una vida desarticulada, por eso cuando quieren contarla dicen "ba-ba-ba" (García Gual, 2000). Lo que ellos hacen no se puede unir ni juntar. Su vida carece de sentido, por eso sus actos no se pueden enlazar en una historia, en un relato. Bárbaros son los hombres con vidas e historias rotas y fragmentadas, sin hilo ni nervio que las vincule. Por acción propia o ajena, su historia biográfica no se puede grafiar, ni se puede hallar su finalidad, que es como carecer de naturaleza. Los dioses tampoco son seres políticos porque no necesitan a otros para alcanzar su plenitud. Esta parece ser la pista principal para entender qué es la politicidad.

A las poleis se acude cuando las acciones y las vidas están articuladas y armonizadas en un relato con sentido, que se puede contar y grafiar. Si sus vidas son una sucesión de actividades adosadas o yuxtapuestas, lo bárbaro es una pluralidad sin más: "ba-ba-ba". 
Así, cuando la vida se ha cuarteado y está hecha a base de fragmentos, "ba-ba-ba", no se puede contar y por eso no tiene sentido comparecer en el espacio público de la polis. Es como tener capacidad de fonación pero de una palabra ininteligible o inaudible para los demás. Un bárbaro es un sujeto disgregado, troceado y dividido. En cambio, un ciudadano es el que sabe que para comprender una vida necesita contarla y contársela a él mismo como si fuese un espectador. Ser ciudadano de la polis es tener la capacidad de integrar y unir la vida en un relato o discurso.

La polis es el lugar de los discursos y el punto de vista de su creación es el del oído. Cuando la vida se ha unido se puede contar y lo puede hacer porque no deja esparcido lo que puede estar unido. No hacerlo es como perder el fin, y como la naturaleza es fin en el mundo griego, carecer de fin es carecer de naturaleza. Nótese que el verbo legein, en griego significa pensar, pero también es unir y enlazar que es lo que hacen los filósofos. Logos significa al mismo tiempo pensamiento y palabra, en suma: discurso. De ahí, la pasión griega por los discursos, la admiración con que eran escuchados y aprendidos, y la relevancia que alcanzaban los que sabían componerlos. Una vida que no se puede contar es una vida degradada, no apta para la polis.

A la polis asisten los que pueden contar su vida, los que le han dado unidad y los que tienen capacidad de discurso cuya palabra es logos. Es verdad que no trabajan con las manos y que sus capacidades no se miden por la perfección de lo que hacen, quizá por eso pueden hablar mejor y su palabra no rebota como el eco, ni clama en el desierto, sino que, al decirla, queda atrapada en otro fuero, resonando en el imperio interior de los iguales que les escuchan con consentimiento y aceptación internas.

Cuando Moisés escuchó la voz de Dios, notó despertar en él una cuerda que vibró y resonó, anota Arendt. No es casualidad que, en el mundo griego, la definición de persona estuviera asociada a la de máscara, porque ese artefacto era el que permitía que lo dicho resonara. Persona viene de resonar y guarda relación con escuchar y no con mirar ni con tocar ni con gustar. Schmitt también constata la relación entre nomos y armonía pues éste "tiene el sentido de una sucesión de tonos, o sea un orden musical" (Schmitt, 2005: 53).

Por eso, porque uno puede "decir y ser escuchado" (Roiz, 2002), puede llegar a acuerdos y a pactos. Y más, puede llegar a ponerse en la situación de los 
demás, que es como ponerse en el lugar desde el que ellos contemplan el mundo y la realidad como si lo oyeran. Así, al "decir" se sabe que los demás se sitúan en los oídos del que habla. El buen político es el que sabe escuchar. Su pensamiento no está tanto ampliado como amplificado, superando la mera opinión, la doxa (Roiz, 2002; Arendt, 1998).

La polis es el lugar desde el que se ve como si se oyera. En ella, los iguales entran en simpatía que, como se sabe, guarda relación con el sonido. Esa simpatía es lo que les permite vibrar juntos como las cuerdas de un arpa. Poder pensar desde el punto de vista de los demás es poder participar de la misma elaboración musical, entrar en armonía con otro tipo de instrumento o caja de resonancia. El pensamiento político es el pensamiento del que está en simpatía auditiva con los demás. Dice Arendt que ese tipo de mentalidad es la que nos permite emitir juicios, aunque referida al ámbito visual no auditivo, porque ya se sabe que para los filósofos el ver prevalece sobre el oír:

La capacidad de juicio es una habilidad política específica en el propio sentido denotado por Kant, es decir, como habilidad para ver cosas no desde el punto de vista personal sino según la perspectiva de todos los que están presentes (1996: 233).

La preeminencia del decir, tanto en Grecia como en Roma, es correlativa a la de la oratoria y la retórica, tan determinantes para la democracia. La polis parece sustentada sobre las maneras de decir. En el decir es donde se pone a prueba la fama del orador y la habilidad para llevar a los iguales y a los conciudadanos a lo justo y verdadero. Por eso en la ciudad, en ese tipo de ciudad, se puede hacer política.

Ya había ciudades muchos siglos antes. Las había en Sumeria, en Babilonia, en Egipto, en Persia, pero no eran poleis, porque allí el decir sólo era hablar, que es como afirmar que uno no era escuchado o que su voz era inaudible para los demás. En esas ciudades lo dicho no se recibía con ese grado de aprobación y resonancia interna de los que participan en la misma aventura de las poleis griegas. Por eso, en éstas no están dormidos, sino atentos y despiertos. Los ciudadanos de la polis están “vigilantes" (Roiz, 2008).

Para que haya política tiene que haber un lugar donde poder decir y poder ser escuchado, incluso poder replicar. En ese espacio de iguales brota la política y la ciudad griega. Una polis es un lugar para decir y ser escuchado. Ahí 
brota una libertad que funda un sistema político entre los que se dan el derecho a decirse y escucharse. Por eso, la retórica, el ars bene dicendi, daría lugar en el mundo romano a la libertad que le era otorgada al ciudadano. Ser ciudadano es poder decir entre iguales y ser escuchado hondamente entre compañeros de aventura, compañeros e iguales que escuchan con imparcialidad. La imparcialidad que tiene Homero al referirse a Aquiles y a Héctor, por ejemplo. Escuchar de esa forma permite el debate, y la deliberatio, la laudatio y la vituperatio, justamente porque lo que se busca es el buen juicio. En las poleis es donde los humanos se convierten en ciudadanos, en zoon politikon y no en las ciudades del primer Neolítico. En las ciudades del "neolítico incipiente" (Liverani, 1995) no había política porque no había libertad, ni había un espacio público donde los hombres actuaran en compañía de los demás, en confianza y con imparcialidad. No tenemos constancia de que hubiera teatros, quizá porque no había posibilidad de actuar ni de interpretar, "solo había espectadores" (Roiz, 2002: 12).

Las ciudades arcaicas son más bien ciudades de déspotas y tiranos, no hay propiamente nomos sino fuerza y mera voluntad (Aristóteles, 2009: III, 7, $1279 b . I V, 10,1295 a)$. El déspota y el tirano se parecen al aristócrata en su emancipación de la necesidad que les permite hacer lo que quieren y vivir sin oposición. Pero la superación de la necesidad no es definitiva para alcanzar la libertad. Hace falta algo parecido a la motivación; esa guía interior que crece en compañía y que guía a los iguales desde dentro. El tirano y el déspota viven como si los demás no existieran. Viven solos, como si las acciones de los demás dejaran de ser una limitación, como si su hablar pudiese no ser escuchado. Silenciar la voz de los demás es como no considerarlos iguales, por eso los déspotas y los tiranos colonizan invadiendo el espacio de la interioridad, subordinándolo a la política, cancelando el derecho de isegoría.

Las ciudades arcaicas no eran poleis porque la política no brotaba de la libertad entre iguales y porque los ciudadanos no actuaban concertadamente: era imposible igualar libertad a poder. En cambio, la polis es el lugar donde los iguales se otorgan el derecho a ser escuchados porque previamente se han dado la confianza, la isonomía (Roiz, 2002). El espacio de la polis es el de los iguales, el de los confidentes, el de los que se fían y por eso confían mutuamente, el de la coacción no violenta, el de la persuasión. La libertad brota ahí, en el lugar 
de la confianza y del derecho a ser escuchado; en el lugar donde aparece el individuo como unidad en sí reconocida y apreciada por sus compañeros ${ }^{5}$.

\section{La polis: el punto de vista del gens.}

En el esquema filosófico y político del estagirita, la ciudad es tenida como telos, esto es, como fin:

Por lo tanto, está claro que la ciudad es una de las cosas naturales y que el hombre es, por naturaleza, un animal cívico. Y el enemigo de la sociedad ciudadana es, por naturaleza, y no por casualidad, o bien un ser inferior o más que un hombre (Aristóteles, 2009: I, 2, 1253a).

Esta noción de polis como algo natural y la naturaleza como telos queda refrendada desde el punto de vista de la lingüística tal y como ha puesto de relieve Émile Benveniste (1999: 274-282) de manera más que sugerente. Para el lingüista francés, la noción de polis es previa a la de polities, en suma: es la noción de polis la que determina el estatuto de polities, rasgo completamente inverso a la noción de civitas, que procede de civis (ciudadano) y que más adelante se verá.

Para ser ciudadano griego se ha de ser miembro de la polis. Solo quien participa de ella, de derecho, recibe atribuciones y honores. El ciudadano es quien participa de una entidad primigenia y no solo eso, esa participación es por referencia al lugar al que se pertenece, al lugar de nacimiento. El estatuto del ciudadano liba de su intrínseca relación con la polis. Ciudadano, polities, es quien pertenece a una ciudad que es suya pero que le antecede como su origen. Desde aquí se entiende que Aristóteles tuviera a la ciudad como "anterior a la casa y a cada uno de nosotros (...) Y el que no puede vivir en sociedad, o no necesita nada por su propia suficiencia, no es miembro de la ciudad, sino como una bestia o un dios" (2009: I, 3, 1253a), situándola entre las cosas que existen por naturaleza ligadas a la esencia de la humanidad y a ese privilegio del hombre que es el lenguaje.

El coeficiente de dilatación de las ciudades griegas está limitado por su genos, porque el logos griego es griego y no indio; algo impensable para un ciudadano romano, como más adelante se verá. La idea de ciudad griega está

\footnotetext{
${ }^{5}$ Los espacios donde se puede hablar, pero no decir porque no se es escuchado, donde cabe la sospecha, pero no la confianza mutua y recíproca no son espacios políticos. Tal es el caso de la familia griega y la tiranía que son tenidas como formas pre-políticas.
} 
vinculada con la noción de origen, resultando que la polis guarda una relación intrínseca con el arraigo, algo completamente distinto a la civitas romana. La polis debiera entenderse como el lugar del ethos, el lugar que sirve como sede de una gente, (gens/genos). En este sentido, una polis no es una civitas porque lo que determina el término polis es una ontología pero también una genealogía: la polis es el lugar del ethos. En suma, la ciudad griega es la sede de un conjunto de personas que participan y comparten un genos concreto, un todo orgánico, biológico incluso étnico, anterior al propio ciudadano. El logos es el logos griego.

Para Cacciari en las poleis griegas prevalece el principio "pertenezco a esta polis porque allí tiene la sede mi genos" (2010:12). Este principio no imposibilitaba que hubiera pactos entre diferentes poleis, pero cada una de ellas preservaba su estirpe y su género, por lo que a pesar de cuantos pactos llevaran a cabo, permanecían genuinamente aisladas. Es justamente esta noción de genos y de ethos lo que mantiene aisladas a unas poleis respecto de otras; por eso el mundo heleno no puede alumbrar unidades federadas más amplias porque no pueden absorber ni metabolizar ontológicamente lo distinto, algo, por otra parte, completamente opuesto a lo que sucederá con las civitates romanas, capaces de integrar lo diverso. Por eso uno de los puntos de vista desde los que abordar la civitas romana sea el de la Concordia que recorre la obra de Tito Livio y que se encuentra en la estructura fundante de la historia romana, no en vano Roma se funda sobre la confluencia de pueblos diversos y su fuerza aglutinadora no obedece a un origen sino a un acuerdo y un objetivo común. Roma no convoca, ni reúne, ni unifica a los ciudadanos ni en la sangre, ni en un pasado común sino en un fin que es común (Cacciari, 2010: 14).

Hasta el punto la polis es selectiva respecto de su genos que, quien no participa del mismo, solo adquiere la condición de meteco, en suma de huésped pero no la de ciudadano. En efecto, las poleis toleraban al extranjero reconociéndoles derechos personales, incluso libertad de culto, pero en modo alguno se le concedían derechos políticos. La polis es étnica y su democracia también, si no sería una civitas romana. Platón y Aristóteles dan cuenta de ello. Platón hace una emocionada defensa del linaje, del lugar de crianza, de la patria y la tierra griegas, en definitiva del gens en Menéxeno, la oración fúnebre que pone en boca de Sócrates recordando el discurso de Aspasia: 
Creo que es preciso hacer su elogio según el orden natural en que han sido valientes. Valientes lo fueron por haber nacido de valientes. Elogiemos, pues, en primer lugar, su nobleza de nacimiento y, en segundo lugar, su crianza y educación. (...) Primer fundamento de su noble linaje es la procedencia de sus antepasados, que no era foránea ni hacía de sus descendientes unos metecos en el país al que habían venido desde otro lugar, sino que eran autóctonos y habitaban y vivían realmente en una patria, criados no como los otros por una madrastra, sino por la tierra madre en la que habitaban, y ahora, después de muertos, yacen en los lugares familiares de la que los dio a luz, los crió y los acogió. Por tanto, lo más justo es tributar, en primer lugar, un homenaje a la madre misma, porque de esta forma resulta enaltecida, además, su nobleza de nacimiento. Nuestro país es digno de ser alabado por todos los hombres y no sólo por nosotros, por muchas y diversas razones, la primera y principal porque resulta ser amado de los dioses. Da fe de esta opinión nuestra la disputa y el juicio de los dioses que por él rivalizaron entre sí. Si los dioses lo han elogiado, ¿cómo no va a ser justo que lo elogien todos los hombres? Se le debería en justicia otro elogio. Que en aquel tiempo en que toda la tierra producía y hacía crecer animales de toda especie, salvajes y domésticos, entonces la nuestra se mostró estéril y limpia de bestias salvajes y de entre los seres vivos escogió para sí y procreó al hombre, el cual sobresale entre los demás seres por su inteligencia y es el único en reconocer una justicia y unos dioses. (...) Pues bien, nuestra tierra y, al propio tiempo, madre nos da una prueba convincente de que ha engendrado hombres: (...) Y después de haberlos criado y haberlos hecho crecer hasta la juventud, ha introducido como sus gobernantes y educadores a los dioses, cuyos nombres -que ya conocemos- conviene omitir en una ocasión como ésta. Ellos han organizado nuestra vida de cara a la existencia cotidiana, al habernos educado, los primeros, en las artes y habernos enseñado la adquisición y el manejo de las armas para la defensa de nuestro país (Platón: 237a -238b).

Y el estagirita, que era meteco, aborda en la Política las causas de las revueltas y las revoluciones, poniendo el acento en la falta de homogeneidad de raza y en la concesión del derecho de ciudadanía a los extranjeros:

(...) pues igual que una ciudad no surge de una aglomeración fortuita, así tampoco de repente. Por ello todos los que admitieron colonos ajenos al emprender una fundación o más tarde, casi siempre acabaron reñidos con ellos; por ejemplo, con los trecenios los aqueos fundaron Síbaris y luego, al 
aumentar los aqueos, echaron a los trecenios; de donde sobrevino la maldición a los sibaritas. También en Turios los sibaritas se enemistaron con sus compañeros de fundación (...) En Bizancio, los colonos, al ser sorprendidos en conspiración, fueron expulsados por las armas. Los antiseos, que habían dado asilo a los fugitivos de Quíos, los echaron de su país con las armas (...) (Aristóteles, 2009: V, 3, 1303a-1303b).

\section{Los espacios políticos: el punto de vista de la Res-pública.}

Con el desarrollo del Imperio Romano la idea de nomos evoluciona definitivamente hacia la noción de mandato, disposición y ley, propia del sentido cesarista del gobernante político (Schmitt, 2005: 58). El nomos espacial y el filosófico deriva hacia el concepto de disposición de disposiciones, cuya gestión se lleva a cabo a través de un Derecho al que se somete todo ciudadano que quiera serlo en el Imperio Romano.

La teoría política romana entiende la ciudad como una comunidad jurídica de hombres libres. Fue Marco Tulio Cicerón quien llevó a cabo un sistema de unificación y organización del Imperio que se expresaba y activaba en el ius civilis. A diferencia de Aristóteles que utiliza la expresión "todos los hombres", Cicerón utiliza la fórmula "el género humano" porque el romano posee una noción de unidad de la estirpe humana que el griego no tenía (Choza, 2009: 58). Los ciudadanos no son solo aquellos que viven en la ciudad como los que están vinculados y articulados por un derecho común y esos pueden ser los que forman parte del "género humano". Así lo anota Cicerón en los libros I y VI de Sobre la Republica:

Pero cuando los pueblos conservan su derecho, niegan que pueda haber algo mejor, más liberal y más feliz, ya que son entonces señores de las leyes, de los juicios, de la guerra y de la paz, de los tratados con otros pueblos, de la vida de todo ciudadano y del dinero (1991: I, 32,48).

(...) pero pueblo no es todo conjunto de hombres reunido de cualquier manera, sino el conjunto de la multitud asociada por un mismo derecho, que sirve a todos por igual (1991: I, 25,39).

Nada hay de lo que se hace en la tierra, que tenga mayor favor cerca de aquel dios sumo que gobierna el mundo entero que las agrupaciones de hombres unidos por el vínculo del derecho, que son las llamadas ciudades (1991: VI, 13(3),13). 
Ciertamente, en el ámbito urbanístico se pueden hallar similitudes entre las ciudades ideadas por griegos y romanos. Nótese las referencias a la situación de la ciudad respecto del mar, su emplazamiento, condiciones de salubridad, ambientales o de comunicación que apreciamos en la obra de Livio y de Vitruvio, y que podemos comparar con las ciudades ideales de Platón o las propuestas aristotélicas referidas en la Política. No obstante, hay una diferencia sustancial. La polis griega tiene por principio rector el nomos (espacial, filosófico y genético), en tanto la civitas romana tiene por principio el ius. El ius es el soporte real de la ciudad y de la ciudadanía romana. En efecto, hace falta un soporte material, pero la característica determinante de la ciudad es de índole jurídica, siendo así que es el derecho el que otorga la ciudadanía no el territorio ni las creencias religiosas ni el linaje.

Lo que Roma descubre es que el ciudadano lo es más por el derecho que por el territorio y por eso es posible que el estratega Nicias arengara a su ejército en las playas de Siracusa en estos términos: "Vosotros mismos sois la ciudad, allá donde decidáis asentaros (...) pues una ciudad consiste en sus hombres, no en unas murallas, ni en unas naves sin hombres" (Tucídides: VII, 77, 7). La ciudad no es tanto el espacio físico donde los hombres desarrollan actividades de índole diversa, como el modo en que queda reflejado y ordenado el comportamiento de los que se ajustan al ius. De manera que lo jurídico y lo institucional no deben pensarse como algo complementario a la ciudad sino como el momento segundo de un mismo movimiento: el de la fundación de una ciudad. Así, tal y como nos ha llegado por Tito Livio en Ab urbe condita, tras cumplirse los ritos de fundación de la ciudad, Rómulo entregó a sus seguidores un primer ordenamiento jurídico:

Después que se hubieran cumplido las los deberes de la religión, Rómulo llamó a su gente a un concilio. Como nada podía unirlos en un solo cuerpo político, sino la observancia de las leyes y costumbres comunes, les dio un cuerpo de leyes, que pensaba que sólo serían respetadas por una raza de hombres incivilizados y rudos si les inspiraba temor al asumir los símbolos externos del poder (I, 8).

La fundación de una ciudad se desarrolla en dos vertientes: una primera, de índole ritual y sacro, ajustándose a las indicaciones del rito etrusco (Rykwert, 2002), y una segunda, centrada en la institución de un ordenamiento político y social (Martínez-Pinna, 1989: 207). Como se ve el ius es una idea 
mucho más poderosa que el nomos griego y precisamente por eso "el ciudadano que es capaz de imponer a todos los demás, con el poder y la coacción de las leyes, lo que los filósofos con sus palabras difícilmente pueden inculcar a unos pocos, debe ser más estimado que los maestros que enseñan tales cosas" (Cicerón, 1991: I, 3).

La organización política romana no puede considerarse como una simple continuación de la polis griega, ni siquiera como una producción a gran escala del modo de vida griego. El ius da lugar a la "cosa" más romana entre las romanas las Res-pública. Para ello es necesario colocarse ante el mundo de manera diversa a la griega y no como continuación.

El empeño romano se centra en dominar, o si se prefiere en gobernar la vida, y a eso, justamente a eso, se le llama urbanización o romanización. Por tanto, el lado fuerte de la vida humana no gira en orden al entendimiento (“...maestros que enseñan tales cosas") sino en orden a la voluntad (“...imponer a los demás con el poder y la coacción de las leyes"). Ante la voluntad romana todo va plegándose dócilmente. Los objetos se convierten en cosas sujetas a la potestad del hombre. La ratio del ius no se halla en un plano superior al derecho sino en la misma realidad por él configurada: la propiedad, la familia, el tráfico, el comercio. La razón del ius está en las relaciones que la práctica del señorío de la voluntad ha hecho nacer. Esas relaciones tienen en sí mismas una naturalis ratio que se representa en el ius. Lo que el derecho plasma es realmente lo útil, lo conveniente y al cabo lo mejor. La historia política de Roma es la de la paulatina impregnación de la comunidad romana por el derecho hasta su conversión en Res. Y ese el nuevo principio universal del configuración de la ciudadanía.

La tensión expansiva del Derecho romano, apoyada en la voluntad, es bien diferente del nomos griego. La polis helena es por esencia una figura cerrada y construida desde su propio nomos. Todo está sometido al nomos. En cambio, el ámbito del ius romanum es el orbis terrarum, su alcance y fuerza de penetración no conoce límites, pues lo que el Derecho define es lo que la voluntad puede dominar.

El grado de unificación entre hombres se lleva a cabo mediante el ius civile, que entendemos como un sistema unitario de relaciones normativas ideales. De modo que la verdadera unificación de los diversos seres humanos queda articulada mediante el espacio del derecho bajo un poder político único. La 
articulación del género humano, de la diversidad de seres humanos, les permite formar parte, no tanto de una comunidad espacial sino máximamente humana, a saber, la humanitas (Choza, 2009: 59). Pueden identificarse y articularse todos los hombres de todos los pueblos, urbi et orbe. La tierra queda abarcada mediante una geografía y una geometría que grafían y miden, pero también dominada por una voluntad de unificación mediante un poder político. El urbanismo es político y administrativo; tutela y defiende el urbi et orbe.

Este proceso se inicia con la época del reinado del primer sabino, Numa Pompilio, que supone un salto cualitativo en el proceso de formación de la ciudad de Roma y que empieza a definirse como una comunidad unida y organizada. Para ello es necesario superar la fase gentilicia en cuya virtud la integración y participación política está vinculada a los lazos de parentesco, de modo que todos sus habitantes se tengan como sujetos de una comunidad política pasando a un segundo orden los linajes y las estirpes (MartínezPinna, 1989: 209). Hasta que lo civil no pesa más que lo gentil no podemos hablar estrictamente de Roma como genuina civitas. Para ello es preciso romper la cerrada y opaca estructura de organización gentilicia tradicional, y eso se lleva a cabo mediante: el culto a Júpiter como divinidad poliada, la aparición de una rudimentaria administración, la creación de un ejército ciudadano que supere las milicias gentilicias y la integración del campo en el seno de la organización urbana (Martínez-Pinna, 1989: 209).

\section{Una civitas no es una polis: el punto de vista de la Concordia.}

La diferencia fundamental entre una polis y una civitas es la diferencia entre un origen y un fin, entre estirpe y ley (Cacciari, 2010: 9). Y más: es la diferencia entre entrar en conflicto con la tensión a la universalidad reduciendo el ámbito de influencia al límite de la ciudad, y entrar en conflicto teniendo por ámbito de influencia el orbe mundo.

La noción de polis está mediada por su genos. Y su ethos también. "Pertenezco a esta polis porque allí tiene la sede mi genos" (Cacciari, 2010: 12). Este carácter de la polis, este ser el lugar de un ethos y sede de una gente (gen/genos) le otorga una dimensión genealógica que es anterior al estatuto de ciudadano y que no encuentra su homólogo en la noción de civitas romana. La polis produce polities, ciudadanos cuya democracia gobierna sobre la base de un sustrato étnico y religioso. En efecto había muchas poleis, incluso pacta- 
ban entre ellas pero cada una de ellas se mantenía "a salvo", de las demás como consecuencia de sus diferentes linajes y estirpes. Tal es el motivo por el que los pactos y acuerdos entre poleis no generaban un cuerpo político más amplio, una federación. La polis griega no puede metabolizar ni integrar lo distinto. Ciertamente ser libre en la polis pero no gozar del mismo genos privaba del estatuto de ciudadano, en cambio podían aspirar a la condición de metecos, como el propio Aristóteles, o de huéspedes. El mundo griego "tolera" extranjeros. A ellos se les reconocen derechos peculiares, identidades y tradiciones singulares, hasta libertad de culto, pero no el ejercicio del derecho político porque pertenecer jurídicamente a una polis es tenerla como sede de un genos. Lo que une a los griegos es su genos. Cada polis agota su raza y radicalizada esta postura, su especie. El nomos griego que servía para dividir y repartir y del que se seguía el ordenamiento es ontológico pero también es genealógico y étnico. Como hemos indicado, éste parece ser el motivo de la preocupación aristotélica y platónica por el crecimiento en exceso de las poleis que podemos comprobar tanto en la Política, la República o las Leyes. El crecimiento desmesurado no solo arriesga la organización interna de la polis, también expone el aseguramiento del arraigo a sus genes.

Apunta Émile Benveniste en Problemas de lingüística general II (1999: 275) que civitas procede de civis. Civis es el término primario y civitas es su derivado. Además civis se traduce injustamente por ciudadano, anota el lingüista francés, cuando en la época clásica el término civis se construía con un pronombre posesivo. Es frecuente leer expresiones como civis meus y cives nostri. La traducción correcta debiera ser la de su uso: conciudadano, mi ciudadano, etc. La cuestión no es irrelevante porque entonces la consideración de "civis para mí", es la de "aquel de quien soy civis". Un civis lo es para otro civis. Es un término que exige reciprocidad. Su estatuto es de naturaleza mutua. Así aparece en Plauto (facilem hanc rem meis civibus faciam), en Tito Livio (invitus quod sequius sit de meis civibus loquor), en Varrón (non sine causa maiores nostri ex urbe in agris redigebant suos cives), de Cicerón (cives nostri), en el mismo César (ne cives cum civibus armis decertarent) y así se sigue usando en la misma Vulgata en Lucas 19,14 la expresión: cives eius (Benveniste, 1999: 276-277). De modo que no hay propiamente civis fuera de esta dependencia recíproca. El abstracto de civis, civitas, aparece como el conjunto de los cives que mantienen una relación de reciprocidad. Y civilis es tenido como aquello que ocurre entre 
cives, no en una civitas. Esta relación de subordinación de la civitas respecto de civis es la que se produce entre el término societas y socius o entre sodalitas y sodalis o entre nobilitas y nobilis (Benveniste, 1999: 280).

Por el contrario, la relación intralingüística referida a polis y poleis es justamente la inversa. Nótese que polites es el derivado de polis. El término primario es polis y el derivado es polites, aquel que participa en la polis y que con muy poca frecuencia se presta a su construcción con un pronombre posesivo. En griego el nombre de la institución es el origen del participante en la misma. Tal es el caso, anota Benveniste, de thíasos (thiasites), phule (phuletes), phatra (phratritas).

Esta singularidad intralingúística entre polis y civitas alumbra una diferencia sustancial entre ambos conceptos. La polis es una entidad abstracta que determina el estatuto de polities, en suma: el que participa y asiste a la polis. El ciudadano de la polis participa de una entidad anterior a él, que hace referencia a un nomos, a un origen, lugar de pertenencia, título de nacimiento, etc. La relación del ciudadano con la polis es entonces de subordinación, de pertenencia. Y no en vano, el propio Aristóteles considera la polis como anterior a toda agrupación humana (2009: I, 2, 1253a).

Civitas en cambio, se convierte en el abstracto de civis. Y así sucede, como se ha indicado, con los términos societas, soladitas y nobilitas. La civitas es la conjunción de personas en orden a un fin. Ese es justamente el origen de la civitas. Es el producto más acabado del conjunto de personas que se aglutinan en una misma sede y en el sometimiento a unas leyes. Además, esta concurrencia de personas de orígenes y creencias múltiples y variadas es lo sustancial de la civitas. En ella, la concurrencia se materializa con independencia de la genealogía. La civitas no remite a un sujeto ni a un origen genealógico y orgánico previo al estatuto de ciudadano. Los cives se agrupan (civitas) y asocian (societas) bajo un único acuerdo: la Ley y el Derecho. No es casualidad por tanto que el punto de vista sobre el que se funda Roma sea el de la Concordia. Y es este punto de vista el que atraviesa la obra de Tito Livio. Así aparece reflejado en el Libro I de $A b$ urbe condita y así pasará a ser tan determinante y constitutiva de la ciencia y las filosofías occidentales:

Desde este punto hay una doble tradición. Según una, Latino fue derrotado en la batalla e hizo la paz con Eneas y, posteriormente, una alianza 
familiar. Según la otra, mientras que los dos ejércitos se encontraban dispuestos a enfrentarse y a la espera de la señal, Latino avanzó desde sus líneas e invitó al líder de los extranjeros a parlamentar. Él le preguntó qué clase de hombres eran, de dónde venían, lo que había ocurrido para hacerles abandonar sus hogares y qué buscaban cuando llegaron al territorio del Lacio. Cuando se enteró de que los hombres eran troyanos, que su jefe era Eneas, hijo de Anquises y Venus, que su ciudad había sido quemada, y que como exiliados sin hogar estaban buscando un lugar para asentarse y construir una ciudad, quedó tan impresionado con el porte noble de los hombres y de su jefe, y su disposición a aceptar tanto la paz como la guerra, que le ofreció su mano derecha como compromiso solemne de amistad para el futuro. Un tratado formal se realizó entre los dirigentes y se intercambiaron saludos entre los ejércitos. Latino recibió a Eneas como invitado en su casa y allí, en presencia de sus penates, completó la alianza política con otra doméstica y dio a su hija (Lavinia) en matrimonio a Eneas. Este hecho confirmó a los troyanos en la esperanza de que habían llegado al término de sus viajes y ganado un hogar permanente. Construyeron una ciudad, que Eneas llamó Lavinio por su esposa. En poco tiempo nació un niño del nuevo matrimonio, a quien sus padres pusieron el nombre de Ascanio (I, 1)

Roma no se funda sobre la base primigenia de una homogeneidad genética, ni sobre un ethos incuestionable, ni sobre un nomos ordenante sino sobre las vidas de aluvión de desterrados y exiliados, errantes, etc. Roma tiene en su origen una "falta de origen", por eso su noción de ciudadanía no tiene raíz alguna de carácter étnico o religioso. Ser romano no es ser griego. Una civitas no es una polis.

Los hombres libres que viven dentro de las fronteras del Imperio están convocados a un fin y no tanto por pertenecer a un polis (donde la naturaleza es fin) como por el acuerdo al sometimiento a unas leyes y eso es lo que Cacciari dice que significa Concordia (2010: 11). Roma tiene un ineludible carácter simbólico cuyo origen no es genealógico como el de Atenas. Su potencia simbólica y aglutinante estriba en ser la sede de las más elevadas instituciones políticas y no la sede de un ethos.

El primado simbólico y político de Roma no obedece a cuestiones étnicas o de raza. La capital del Imperio es la sede de un fin compartido y acordado. Roma es la sede de una estrategia común y de un fin que no se lleva a cabo en 
el pasado genealógico ni en los lazos de sangre: “lo romano no es algo predeterminado, sino precisamente aquello que el vínculo jurídico y cívico construye" (Moatti, 2008: 446) ¿Cuál es el fin de esa mentalidad? "Un imperium sine fine, un Imperio sin fin", anota Cacciari (2010: 14) en clara referencia a la sentencia de Virgilio en La Eneida: "nec metas rerum tempora pono / imperium sine fide dedi". Lo que Roma impone es la Concordia que producen las leyes romanas: lo que rige y gobierna una civitas no es un gens ni un fundamento originario, sino un objetivo común. Ese objetivo no es otro que hacer coincidir la urbe con el orbe. De esta forma supera Roma a Atenas, y la civitas a la polis. Atenas era estática. Roma dinámica e independiente del lugar porque su ethos es un acuerdo, una creación y no una subordinación. Su magnitud simbólica no está ligada a un lugar ni a una genealogía local sino a un fin que no es naturaleza sino una creación o si se prefiere una invención "que tiende a una sociedad universal" (Cellurale, 2009: 39). Roma supera la valla ontológica, eso significa nomos, y la traza genealógica que delimitaba el limes de la polis y que acabó por ensimismarla. Roma tiene por fin hacer coincidir el límite de la urbs con el del orbe, el perímetro del mundo.

Un civitas lleva dentro de sí la semilla del delirio ¡Roma delirante! ${ }^{6}$. El delirio consiste en salirse fuera del surco trazado, de la lira. Para un romano, cuyo principio inspirador es el imperium sine fine tanto espacial como temporal, es completamente inimaginable una ciudad que no delire (Cacciari, 2010).

¿Qué parece ser lo natural de la civitas? Crecer y además ilimitadamente, en suma delirantemente, pero sobre la base de la Concordia en el sometimiento al Derecho. La idea de crecer ilimitadamente resulta algo completamente ajeno e inaudito a las poleis griegas. En cambio, el coeficiente de dilatación temporal y espacial de las ciudades romanas era ilimitado; tenía por límite el mundo. Lo que explica que una de las principales actividades y pasiones de los emperadores romanos fuera la fundación y refundación de ciudades, actividad por otra parte considerada una obligación:

Desde Alejandro, uno de los deberes tradicionales del rey era fundar ciudades, y esta tradición todavía permanecía acusadamente, en la parte oriental del Imperio (Jones, 1964: 719).

\footnotetext{
${ }^{6}$ Este calificativo "delirante", falta de límite y posibilidad de crecimiento indefinido, guarda estrecha relación, a nuestro juicio, con el contenido del libro de Rem Koolhaas, Delirious New York, (2004).
} 


\section{Conclusión.}

Una polis genera polities. Una civitas es generada por civies. Una polis se funda sobre un ethos que es la sede de un genos. Una civitas es la creación, la invención de un conjunto de personas de origen y religiones diversas que acuerdan el sometimiento a una ley y un derecho. Tal es el significado de Concordia. Su identidad es extrínseca a su raza. Una polis está delimitada por un nomos, por una valla. Una valla física, ontológica y genealógica. Hace referencia a sí misma y aunque pueda llegar a pactos con otras poleis no es capaz de constituir una federación estable. En cambio, una civitas tiende inexorablemente a crecer. Esa es su naturaleza y al cabo su finalidad: ser universal y eterna. Y para administrar y gobernar ese crecimiento acuerda el sometimiento al ius que se proyecta por siempre y para todos los hombres de todos los pueblos. Un civitas es delirante y con frecuencia programáticamente bilingüe. Un polis es lógica, étnica, y constantemente monolingü̈ ${ }^{7}$.

\section{Bibliografía.}

ARENDT, Hannah (1996). Entre el pasado y el futuro. Península. Barcelona.

ARENDT, Hannah (1998). La condición humana. Paidós. Barcelona.

ARISTÓTELES (2009). Política. Alianza Editorial. Madrid.

BENVENISTE, Émile (1999). Problemas de lingüística general II. Siglo Veintiuno Editores. Decimoquinta edición en español. Madrid.

BURKERT, Walter (2009). La creación de lo sagrado. La huella de la biología en las religiones antiguas. Acantilado. Barcelona.

CACCIARI, Massimo (2010). La ciudad. Gustavo Gili. Barcelona.

Cellurale, Mariateresa (2009). “Locus e ius: observaciones sobre espacio y sistema a la luz del derecho romano". Revista de Derecho Privado, núm. 16, enero-junio, 2009, pp. 31-48 Universidad Externado de Colombia Bogotá, Colombia. ISSN: 0123-4366.

CHOZA, Jacinto (2009). Historia cultural del humanismo. Thémata- Plaza y Valdés. Madrid.

CHOZA, Jacinto (2014) Filosofía de la cultura. Thémata. Sevilla.

\footnotetext{
${ }^{7}$ La literatura griega no cita, ignora, a autores latinos como Virgilio, Horacio, Ovidio y Lucrecio desde el siglo I al VI d. (Cacciari, 2010: 16).
} 
CiCERÓN, Marco Tulio (1991). Sobre la república. Gredos. Madrid.

COULANGES, Fustel (2009). La ciudad antigua. Edaf.11ª ed. Madrid.

FINLEY, Moisés I. (1984). La Grecia antigua. Economía y sociedad. Grijalbo. Barcelona.

GARCÍA GUAL, Carlos (2000). Identidad y mitología. Apuntes sobre el ejemplo griego. En: Identidad humana y fin del milenio. Actas del III Congreso Internacional de Antropología filosófica, Barcelona, 1998. Thémata. Sevilla.

HALICARNASO, Dionisio de. II, 7, 2-4.

HERÁCLITO, Fragmento 22B 44DK.

JONES, Arnold. H. M. (1964). The Later Roman Empire 284-602. A Social Economic and Administrative Survey, III vols. B. Blackwell. Oxford.

KANT, Immanuel (1989). La Metafísica de las costumbres. Introducción, traducción y notas de A. Cortina y J. Conill. Tecnos (1797). Madrid.

KoOlHaAs, Rem (2004). Delirio de Nueva York. GG. Barcelona.

LIVERANI, Mario (1995). El antiguo oriente. Historia, sociedad y economía. Crítica (Grijalbo Mondadori). Barcelona.

LIVIO, Tito. Ab urbe condita. Libro I.

LOCKE, John (2003). Political writings. Hackett Publishing Company, Inc. Indianapolis/Cambridge.

MARÍN, Higinio (1997a). De dominio público. Ensayos de teoría social y del hombre. Eunsa. Pamplona.

MARÍN, Higinio (1997b). La invención de lo humano. La construcción socio-histórica del individuo. Iberoamericana. Madrid.

MARTíNEZ-PINNA, Jorge. (1989). Algunas reflexiones sobre el nacimiento de la ciudad en el Lacio. Anejos de Gerión, II. Edit. Universidad Complutense. Madrid.

MOATTI, Claudia (2008). La razón de Roma: El surgimiento del espíritu crítico a fines de la República. Antonio Machado Libros. Madrid.

PLATÓN. Leyes, V, 741a.

PLATÓN. Menéxeno. 237a -238b.

ROIZ, Javier (2002). La teoría política de Hannah Arendt. ICPiS, nº. 208. Barcelona.

RoIZ, Javier (2008). Sociedad vigilante y mundo judío en la concepción del Estado. Editorial Complutense. Madrid.

RYKWERT, Joseph (2002). La idea de ciudad. Antropología de la forma urbana en el mundo antiguo. Ed. Sígueme. Salamanca. 
SANCHO, Laura (2009). “Teoría moderna y DemoKratia antigua” en Sancho, Laura. Filosofía y democracia en la Grecia antigua. Publicaciones Universidad de Zaragoza.

SCHMITT, Carl (2005). El nomos de la tierra en el Derecho de Gentes del "Jus publicum europaeum". Edit. Struhart y Cia. Buenos Aires.

TUCíDIDES. Historia de la guerra del Peloponeso. VII. 77,7.

VICO, Giambattista (1839). Scienza nuova VL.4. Stamperia de classici Latini. Nápoles. 